\title{
A TRANSVERSALIDADE DA TEMÁTICA AMBIENTAL NA EDUCAÇÃO PROFISSIONAL: UMA ANÁLISE DOS CURSOS TÉCNICOS INTEGRADOS DO IFS
}

Juliano Azuma da Costa ${ }^{1}$

Kallyne Machado Bonifácio²

Sônia Pinto de Albuquerque Melo ${ }^{3}$

Reinaldo Farias Paiva de Lucena ${ }^{4}$

Resumo: $O$ objetivo desta pesquisa foi analisar a presença da temática ambiental, como Tema Transversal, nos Cursos Técnicos de Nível Médio Integrados ao Ensino Médio do Instituto Federal de Sergipe - Campus Aracaju. Neste sentido, foram analisados, inicialmente, o Projeto Político Pedagógico Institucional do IFS, os Projetos Pedagógicos do Cursos e os Planos de Ensino dos docentes. Em seguida, foram aplicados questionários aos alunos e professores para analisar a presença da temática ambiental nas práticas pedagógicas em sala de aula. Participaram deste estudo 262 alunos e 63 professores dos Cursos Técnicos Integrados em Alimentos, Edificações e Química. Os resultados revelaram que a Educação Ambiental ainda é incipiente no IFS. Há a necessidade de reformulação dos documentos pedagógicos institucionais para que estes sigam diretrizes comuns em relação a Educação Ambiental e retratem a transversalidade.

Palavras-chave: Educação Ambiental; Práticas Pedagógicas; Transversalidade; Política Nacional de Educação Ambiental.

1 Instituto Federal de Educação, Ciência e Tecnologia de Sergipe (IFS), Campus de Aracaju. E-mail: juliano.costa@ifs.edu.br

2 Universidade Federal da Paraíba (UFPB). E-mail: kallynebonifacio@gmail.com

3 Instituto Federal de Sergipe, Campus de Estância. E-mail: sonia.melo@ifs.edu.br

${ }^{4}$ Universidade Federal do Mato Grosso do Sul (UFMS). E-mail: reinaldolucena.dr@gmail.com

Revbea, São Paulo, V. 16, № 2: 232-247, 2021. 
Abstract: The objective of this research was to analyze the presence of the environmental theme, as a cross - Sectional Theme, in the High - Level Technical Courses Integrated to High School of the Federal Institute of Sergipe - Campus Aracaju. In this sense, the Institutional Political Project of the IFS, the Educational Projects of the Courses and the educational plans of the teachers were analyzed. Next, questionnaires were applied to students and teachers to analyze the presence of the environmental theme in the pedagogical practices in the classroom. A total of 262 students and 63 professors from the Technical Courses of Middle Level Integrated to High School in Food, Buildings and Chemistry participated in this study. The results revealed that Environmental Education is still incipient in IFS. There is a need to reformulate institutional pedagogical documents so that they follow common guidelines in relation to Environmental Education and portray transversality.

Keywords: Environmental Education; Pedagogical Practices; Transversality; National Policy of Environmental Education.

\section{Introdução}

Surgido nos anos 1990, no contexto da Educação Básica, o ensino de temas transversais visa ultrapassar a dimensão disciplinar dos conteúdos, requerendo para tal, uma organização curricular que contemple questões relacionadas com o cotidiano dos alunos (BRASIL, 1997; DE-CARVALHO; MATEI, 2019). Isso pressupõe que as discussões desses temas em sala de aula devem mobilizar os conhecimentos das diferentes áreas para entender e explicar a realidade local, a promoção da chamada interdisciplinaridade. Nessa direção, processos pedagógicos contextualizados com temas pertinentes aos alunos podem tornar a aprendizagem mais significativa, tendo em vista, o que 0 aluno aprende, ele consegue colocar em prática (SILVA; RAMOS, 2019; VIÇOSA et al., 2020).

De acordo com os Parâmetros Curriculares Nacionais, os Temas Transversais foram criados para incentivar nas escolas a abordagem de questões emergenciais sociais, e importantes na formação dos alunos. Os temas eleitos a serem trabalhos em todo o currículo escolar, no âmbito da sua realidade local e no seu contexto são, Ética, Saúde, Meio Ambiente, Orientação Sexual, Trabalho e Consumo e Pluralidade Cultural (BRASIL, 1997).

No atual panorama de ameaças, a emergência ambiental é evidenciada como uma ameaça global ao bem-estar humano e ao planeta que dialogam com os Objetivos de Desenvolvimento Sustentável (ODS), ações adotadas por todos os líderes de Governos e Estados integrantes da Organização das Nações Unidas (UNITED NATION, 2015). Dado a esse fato, possivelmente, esse é um tema contemporâneo potencial para perpassar um maior número de componentes curriculares em projetos, atividades (visitas técnicas), eventos, cursos de formação etc., tanto na Educação Básica e como no Ensino Superior.

Revista brasileira educação ambiental 
Há que se destacar que os currículos integrados, por sua natureza, tendem a apresentar eixos transversais. A forma Integrada implica na articulação entre os conteúdos de formação geral e específica, considerados essenciais para a compreensão dos processos produtivos e da realidade mais ampla (RODRIGUES et al., 2020). Segundo a Lei 11.892/2008, que dispõe sobre os Institutos Federais, essa é uma característica da Educação Profissional. As modalidades de ensino ofertadas pelas instituições que compõem a Rede Federal de Educação Profissional buscam a formação integral do aluno por meio de um currículo fundamentado em três eixos, Ciência, Trabalho, Cultura e Tecnologia.

O Instituto Federal de Sergipe (IFS), objeto desta pesquisa, embora tenha como missão promover a formação humana integral através da articulação entre ensino, extensão, pesquisa e inovação (IFS, 2015), será que a temática ambiental, proposta pelos Parâmetros Curriculares Nacionais como tema transversal, está sendo abordada nas práticas pedagógicas dos seus Cursos Técnicos de Nível Médio Integrados ao Ensino Médio?

Conforme o previsto na Lei 9.795/1999, sobre a Educação Ambiental, "em todos os níveis e modalidades de ensino devem ser incorporados conteúdos que tratem da ética ambiental das atividades profissionais a serem desenvolvidas". A propósito, no que se refere ao tema transversal meio ambiente, convém destacar que não se reduz apenas ao ambiente físico e biológico, mas abrange também as relações sociais, econômicas e culturais (OLIVEIRA; SAITO, 2014).

Assim, o objetivo deste estudo foi avaliar a inserção de temas relacionados com o meio ambiente nos Cursos Técnicos de Nível Médio Integrados ao Ensino Médio do Instituto Federal de Sergipe (IFS) - Campus Aracaju, mediante a análise de Documentos Normativos (Projeto Político Pedagógico Institucional, Projetos Pedagógicos dos Cursos e Planos de Ensino dos professores), e análise da percepção dos professores sobre os PCNs.

\section{Metodologia}

Criado em 2008 pela Lei 11.892, o Instituto Federal de Sergipe (IFS) conta com nove Campi espalhados por todo o Estado de Sergipe. O Campus Aracaju oferece os Cursos Técnicos de Nível Médio Integrados ao Ensino Médio de Alimentos, Edificações, Eletrônica, Eletrotécnica, Informática e Química, que são cursos técnicos articulados ao Ensino Médio, com duração de quatro anos.

Dentre os Cursos Técnicos Integrados do Campus Aracaju, foram escolhidos como objeto da pesquisa os cursos de Química, Alimentos e Edificações, totalizando 12 turmas estudadas (4 turmas por curso). A escolha dos cursos se deu por se acreditar em uma maior relação destes com a temática ambiental. $O$ quantitativo de alunos matriculados nos 03 cursos durante a realização dessa pesquisa correspondeu a 408 alunos. 
Usando a classificação de Gil (1995), esta pesquisa foi do tipo descritiva, de caráter explicativa, com abordagem qualitativa. Quanto aos meios de investigação, sua natureza é documental e pesquisa de campo.

Os documentos analisados foram o Projeto Político Pedagógico Institucional (PPPI) do IFS, os Projetos Pedagógicos dos Cursos (PPC), ambos disponíveis no site do IFS, e os Planos de Ensino dos professores, que foram solicitados aos docentes que responderam aos questionários. Além disso, foram elaborados dois questionários distintos direcionados aos alunos $e$ professores para averiguar de que forma os conhecimentos concernentes ao meio ambiente estão sendo inseridos na organização curricular (como conteúdos de componentes ou se pela transversalidade).

A aplicação dos formulários de entrevistas aos alunos $(n=262)$ ocorreu em sala de aula, com a autorização do professor da disciplina, durante os meses de julho e agosto de 2016. Foram realizadas duas visitas: a primeira, para entrega dos Termos de Consentimento Livre e Esclarecido - TCLE, pois a maioria dos alunos era menor de idade, portanto, deveriam trazer o TCLE assinado pelos pais ou responsáveis. Na segunda, para os alunos que trouxeram o TCLE assinado, foram entregues os Termos de Assentimento para que eles assinassem. Somente os que assinaram os Termos de Assentimento e trouxeram os TCLE assinados pelos pais, participaram da pesquisa, além dos alunos maiores de 18 anos que assinaram o TCLE.

No caso dos professores, a aplicação do formulário de entrevista se deu através de abordagem presencial no próprio Campus Aracaju ou em horário marcado com agendamento realizado através de contato prévio, entre os meses de setembro e dezembro de 2016. Dos 75 professores que ensinavam pelo menos uma disciplina nos Cursos Integrados de Alimentos, Química e Edificações, apenas 63 responderam o formulário.

Sobre a análise dos dados, para os documentos, foi realizada através de uma primeira leitura detalhada a fim de identificar a presença de termos e conteúdos relacionados à temática ambiental, além de ideias que remetessem a formação de alunos cidadãos, responsáveis socialmente e conscientes com o meio em que vivem.

Em relação aos formulários de entrevistas, os dados foram analisados pelo método de análise de conteúdo, que, conforme Vergara (2005), consiste em uma técnica que apura os dados coletados, objetivando a identificação e caracterização do que está sendo dito a respeito de determinado tema 


\section{Resultados e Discussão}

\section{Análise do Projeto Político Pedagógico do IFS}

O Projeto Político Pedagógico do Instituto Federal de Sergipe (IFS), que recebe a nomenclatura de Projeto Político Pedagógico Institucional (PPPI), foi concebido com o objetivo de "retratar e nortear as ações educativas" do IFS e "harmonizar as Diretrizes da Educação Nacional com a realidade da instituição, traduzindo sua autonomia bem como definindo seu compromisso social" (IFS, 2015).

Para Bilert et al. (2014), o Projeto Político Pedagógico é um instrumento teórico-metodológico que norteará as práticas acadêmicas para o exercício do ensino, pesquisa e extensão e devem orientar os PPCs dos cursos.

A última versão do PPPI foi concebida em 2015, mediante a criação da Comissão de atualização do Projeto Político Pedagógico Institucional do IFS, oficializada pela Portaria № 2.093, de 30 de julho de 2015, sendo formada por pedagogos dos diversos Campi da Instituição.

A primeira referência à temática ambiental no PPPI do IFS se dá no capítulo 3 (Breve Histórico Institucional), que faz uma apresentação do IFS desde a sua criação até a última fase de expansão, e trata das finalidades, características, objetivos, missão e visão do IFS. Na realidade, o texto foi retirado da Lei 11.892, de 29 de dezembro de 2008, que institui a Rede Federal de Educação Profissional, Científica e Tecnológica, cria os Institutos Federais de Educação, Ciência e Tecnologia, e dá outras providências. De acordo com a Lei, em seu Art. 6으, inciso IX, o IFS tem como uma de suas finalidades e características promover a produção, o desenvolvimento e a transferência de tecnologias sociais sustentáveis, notadamente as voltadas à preservação do meio ambiente. Ou seja, o fomento de novas tecnologias deve se basear na sustentabilidade e considerar a conservação do nosso ecossistema.

No capítulo 4 (Na Interação com os Problemas Locais), descreve-se que vivenciamos, devido à globalização, problemas de ordens sociais, políticos, econômicos, culturais, religiosos e ambientais. $\mathrm{Na}$ parte das questões ambientais, citam-se os habituais transtornos ambientais que vivenciamos, como o consumo insustentável dos recursos naturais, diversos desastres ecológicos, as mudanças do ecossistema do planeta entre outros.

As duas primeiras citações relacionadas à temática ambiental no PPPI do IFS não estão ligadas às práticas pedagógicas, aparecendo de forma isolada, não tendo nenhuma referência com a Educação Ambiental em seu contexto mais amplo.

No capítulo 7 (Marco Pedagógico: Desenvolvimento do Currículo), na seção intitulada Concepções Curriculares, o PPPI cita que "Na elaboração dos currículos, busca-se contemplar o processo de construção do conhecimento técnico-científico, que se articula ao espectro de valores humanísticos. A dinâmica e realização dos saberes curriculares se configuram a partir do 
entendimento de que ciência e técnica não se apresentam apenas como meio ou dispositivo, mas, principalmente, como modo de inserção na realidade, promovendo através do ato educativo a capacidade de ação, transformação e interação do homem com o meio.

No capítulo 9, intitulado Diretrizes Pedagógicas, o documento trata dos procedimentos do fazer pedagógico para o desenvolvimento e potencialização de ações que respondam aos desafios que se impõem à consolidação da identidade do IFS, entre os quais: implementar propostas curriculares flexíveis e comprometidas com as questões sociais, éticas e ambientais, relacionandoas às áreas específicas de formação profissional e do tecido social.

Percebe-se, nas abordagens no capítulo 7 e 9, uma preocupação em formar cidadãos, através da concepção dos currículos, não somente com conhecimento técnico científico, mas que compreendam estar inseridos em uma realidade onde suas ações, transformações e interações transformam o meio em que vivem. Defende-se, ainda, a ideia de que as propostas curriculares devem ser flexíveis e comprometidas com as questões ambientais.

Apesar de não retratar a EA de forma incisiva, o PPPI do IFS traz referências à temática ambiental, que indica que esta deve fazer parte da proposta curricular dos cursos. Porém, não retrata os fundamentos teóricos que alicerçam a proposta de Educação Ambiental, como a transversalidade.

\section{Análise dos Projetos Pedagógico dos Cursos}

Os Projetos Pedagógicos dos Cursos (PPCs) do Instituto Federal de Sergipe são desenvolvidos tendo como base o Documento-Referência para Elaboração ou Reformulação de Projeto Pedagógico de Curso. O objetivo principal do documento é subsidiar os trabalhos das comissões designadas, através de portarias, para elaborar ou reformular projetos de cursos no âmbito do IFS, a fim de construir uma identidade institucional, nesse campo, respeitando-se, logicamente, as peculiaridades de cada curso.

$O$ documento referência é dividido nas seguintes partes: Apresentação; Definindo o PPC; A Necessidade de Reformulação dos Projetos Pedagógicos dos Cursos; Parâmetros para a Elaboração de um PPC; e Estrutura de um PPC.

A única alusão à temática ambiental em todo o Documento-Referência para Elaboração ou Reformulação de Projeto Pedagógico de Curso aparece na apresentação da Estrutura de um PPC, que apresenta os elementos constituintes de um Projeto Pedagógico de Curso. Na seção Justificativa, que fundamenta a necessidade de implantação/continuidade do curso, indica-se que a justificativa deve contemplar informações atualizadas sobre os aspectos socioeconômicos e socioambientais da Região Nordeste, do Estado de Sergipe e da mesorregião, pertinentes a área/eixo tecnológico do Curso a ser ofertado. 
Além disso, o capítulo Parâmetros para a Elaboração de um PPC diz que o projeto deve obedecer aos instrumentos normativos institucionais e aos específicos de cada curso, como leis, diretrizes curriculares nacionais, decretos, pareceres e resoluções.

Os Projetos Pedagógicos dos Cursos Técnicos de Nível Médio Integrados ao Ensino Médio em Alimentos, Edificações e Química sofreram reformulação em 2014, principalmente para a adequação da duração de integralização do curso, que passou de 4 para 3 anos.

Os PPCs dos cursos de Alimentos e Química são bastante semelhantes, não somente com relação a abordagem da temática ambiental, mas em todo conteúdo. A seção Justificativa de ambos foi retirada do Documento-Referência para Elaboração ou Reformulação de Projeto Pedagógico de Curso.

Ambos os PPCs dos cursos de Alimentos e Química parecem estar alinhados ao Projeto Político Pedagógico Institucional, pois apontam que a temática deve fazer parte do currículo. No Capítulo Organização Curricular, o documento cita que a arquitetura curricular do curso se propõe a desenvolver a criticidade do estudante para que paute a sua conduta em valores éticos, estéticos e morais, principalmente no que se refere à ética da identidade, adotando como princípio basilar a política da igualdade, a qual se consolidará através do respeito aos direitos de todos e pelo compromisso com a solidariedade e com as questões sócio ambientais (IFS, 2014a,b).

No PPC do curso de Alimentos a temática ainda aparece no capítulo Objetivos Específicos, apontando que o profissional deve visar a melhoria da qualidade e da produtividade, mas também comprometido com as questões éticas e sócio ambientais inerentes a sua área de atuação profissional (IFS, 2014a). Já no PPC de Química, no capítulo Perfil Profissional de Conclusão, é mencionado que o profissional deve atuar com responsabilidade ambiental.

Nas ementas das disciplinas dos cursos de Alimentos e Química, a temática ambiental aparece nas disciplinas propedêuticas com maior proximidade ao tema: Geografia I, Química II, Geografia III, Sociologia II, Biologia II e III. Os dois cursos ainda possuem as disciplinas técnicas Saúde, Meio Ambiente e Segurança no Trabalho e Química Ambiental e Desenvolvimento Sustentável (SMST), ambas dadas no $1^{\circ}$ ano do curso. Ou seja, os dois cursos possuem disciplinas técnicas voltadas para a temática ambiental, nas quais, teoricamente, a abordagem pode ser bem trabalhada.

O curso de química ainda possui duas disciplinas que apresentam em sua ementa a temática ambiental: Microbiologia e Tecnologia de Petróleo e Gás. Porém, a presença é insignificante frente às extensas ementas das disciplinas.

Outro fator importante analisado no PPC do Curso Técnico de Nível Médio Integrado ao Ensino Médio em Alimentos é que o curso possui em seu quadro de professores cinco Mestres em Desenvolvimento e Meio Ambiente. 
O PPC do curso de Edificações, em seu escopo, aborda a temática ambiental em quatro momentos: duas vezes na seção Justificativa e ainda nas seções Objetivo Geral e Perfil Profissional de Conclusão.

$\mathrm{Na}$ Justificativa, o documento relata o processo de urbanização das cidades, principalmente a convivência nos espaços edificados, responsabilizando o Estado na forma de se avançar para políticas de inclusão social atreladas a formas de desenvolvimento mais sustentáveis sob o ponto de vista ambiental. Demonstra, ainda, a preocupação pela "educação e formação de cidadãos mais conscientes e atentos a novas alternativas de coexistência entre o homem e seu meio (IFS, 2014b).

$\mathrm{Na}$ seção Objetivo Geral, cita-se que os profissionais de edificações deverão atuar de maneira proativa, ética e autônoma, com uma visão crítica, capaz de assumir responsabilidades em relação às questões ambientais e sociais. E no Perfil Profissional de Conclusão, alerta que o formando em Edificações deve analisar e orientar a aplicação de medidas de controle e proteção ambiental para redução dos impactos gerados pelas atividades construtivas (IFS, 2104b).

Para Santos e Santos (2016), a prática da EA no ensino formal tem esbarrado em muitos problemas na tentativa de inserção no currículo escolar, mas destaca dois desafios que são consecutivos: grande parte das escolas brasileiras não tem um projeto educativo que contemple a problemática ambiental, e desse modo não pode oferecer aos professores condições propícias para trabalhar coletivamente e de forma integrada.

Em geral, pode-se afirmar que os PPCs dos cursos de Alimentos, Edificações e Química mencionam a temática ambiental, porém, assim como o Projeto Político Pedagógico, não evidenciam as propostas da EA de forma ampla.

\section{Análise dos Planos de Ensino dos Professores}

Dos 63 professores, 79,4\% disseram que usam a ementa da disciplina em substituição aos Planos de Ensino, 9,5\% revelaram não entregar plano de ensino aos alunos e apenas $11,1 \%$ apresentaram o plano de ensino. $\mathrm{Na}$ averiguação dos 07 Planos de Ensino recebidos apenas 1 abordava a temática ambiental. $\mathrm{Na}$ realidade, o Plano de Ensino do docente apresentava todos os temas transversais propostos nos PCN: Ética, Meio Ambiente, Pluralidade Cultural, Saúde e Orientação Sexual. Em seu planejamento, ele objetiva trabalhar um tema transversal por bimestre, sendo que os temas Saúde e Orientação Sexual são trabalhados no mesmo período. A justificativa desse professor abordar a temática ambiental é que os Parâmetros Curriculares Nacionais foram objeto de estudo em sua dissertação de mestrado em Educação. 


\section{Abordagem da temática Ambiental nas Práticas Pedagógicas na visão dos alunos e dos professores}

\section{Percepção dos alunos}

Os alunos participantes da pesquisa possuíam idades entre 15 e 21 anos, distribuídos entre os 1ำ $2^{\circ}, 3^{\circ}$ e $4^{\circ}$ anos do Cursos Técnicos de Nível Médio Integrados ao Ensino Médio em Alimentos, Edificações e Química. Dos 262 alunos, 101 eram do curso de Edificações, 93 de Química e 68 de Alimentos, sendo 158 do sexo feminino e 104 do sexo masculino, com uma predominância de alunos do sexo feminino nos cursos de Alimentos e Química, e uma pequena maioria do sexo masculino no de Edificações.

A primeira pergunta abordou a noção que os alunos tinham de Educação Ambiental, sendo esta a única questão aberta de todo o questionário. As respostas, apresentadas apontaram que, dos 262 alunos que participaram da pesquisa, 28,9\% responderam que a EA está relacionada com a conscientização de pessoas sobre questões ambientais ou meio ambiente. Um dos alunos deu a seguinte definição: "Processo de conscientização pelo qual o indivíduo começa a construir valores sociais, conhecimentos e habilidades para uma boa conservação do meio ambiente".

Por outro lado, uma grande parte dos alunos associa a EA à preservação do meio ambiente $(22,6 \%)$, à reciclagem $(10,9 \%)$, a não jogar lixo na rua $(9,4 \%)$, a não poluir $(7,0 \%)$, a viver em harmonia com a natureza $(2,3 \%)$, a cuidar do Planeta Terra (2,3\%), a não desmatar $(1,6 \%)$ e a não desperdiçar $(1,6 \%)$. Ou seja, muitos têm um entendimento superficial sobre a EA, pois a associam a ações isoladas que possuem relação com a temática ambiental, mas não necessariamente definem o que venha a ser EA. Além disso, 12,5\% não sabiam ou não responderam à pergunta.

Quando questionados se achavam que a temática ambiental deveria ser trabalhada nos Cursos Técnicos de Nível Médio Integrados ao Ensino Médio, $96,5 \%$ dos alunos responderam que sim. Na mesma direção, 96,9\% afirmaram que é papel da escola contribuir para EA da sociedade. Percebe-se que até mesmo os alunos entendem que o ambiente escolar deve contribuir para a EA das pessoas e que a temática ambiental deve permear os conteúdos dos seus cursos.

Na visão de Severino (2010), o Ensino Médio é uma etapa privilegiada do processo educacional para a construção da identidade do adolescente, contribuindo assim para sua formação como cidadão, embora a formação humana não se dê exclusivamente pela mediação dos procedimentos da educação formal.

Portanto, a introdução dos conhecimentos referente à Educação Ambiental nos currículos, não somente, mas principalmente nos Cursos Técnicos de Nível Médio Integrados ao Ensino Médio, é propícia para que os discentes criem uma consciência ambiental, através da abordagem da temática ambiental nas práticas pedagógicas. 
Ademais, a Educação Ambiental é objeto de Lei Federal, que obriga as instituições educativas promoverem a EA de maneira integrada aos programas educacionais que desenvolvam, em todas as suas etapas e modalidades (BRASIL, 1999). As instituições educativas têm o papel de qualificar e conscientizar os cidadãos, formadores de opiniões de amanhã.

Quando indagados sobre com que frequência assuntos relacionados à temática ambiental são tratados em sala de aula, $81,5 \%$ responderam que às vezes $(45,9 \%)$, raramente $(31,4 \%)$ ou nunca $(4,2 \%)$ assuntos relacionados à temática ambiental são abordados em sala de aula. Em contrapartida, apenas $18,7 \%$ disseram que temas relacionados à temática ambiental são abordados frequentemente $(15,6 \%)$ ou Sempre $(3,1 \%)$ em sala de aula. Apesar destes 49 alunos representarem apenas $18,7 \%$ dos participantes, mesmo assim foi um dado que chamou a atenção do pesquisador. Ao realizar os cruzamentos dos dados, observou-se que dos 49 alunos que responderam frequentemente ou sempre, 29 pertenciam às primeiras séries dos cursos de Química e Alimentos, ou seja, apenas duas turmas (1 IQUI e 1은 IALM), de um total de 12, representaram $59 \%$ das respostas.

Analisando-se as matrizes curriculares dos Cursos Técnicos de Nível Médio Integrados ao Ensino Médio em Alimentos e Química, constatou-se a presença das disciplinas Química Ambiental e Desenvolvimento Sustentável e Saúde, Meio Ambiente e Segurança no Trabalho justamente no $1^{\circ}$ período dos dois cursos. Provavelmente, esse fato pode ter influenciado nas respostas dos alunos dessas turmas.

Por fim, ao serem questionados sobre como os professores abordam a temática ambiental em sala de aula, 228 alunos assinalaram que a abordagem era feita relacionada ao conteúdo da disciplina. Ou seja, apesar dos professores tratarem pouco da temática ambiental, quando o fazem, na perspectiva de mais de $90 \%$ dos alunos, é relacionado ao conteúdo da disciplina. Uma possível explicação para esse resultado pode estar na qualificação dos professores, já que alguns apresentam formação na área de meio ambiente ou porque o trabalho dessa temática se restringe a algumas disciplinas (Biologia e Geografia, por exemplo) como conteúdo dos componentes já constantes do currículo (FREITAS et al, 2018).

\section{Percepção dos Professores}

Nos resultados obtidos através da aplicação dos questionários, considerou-se alguns conteúdos das repostas dos docentes e, para assegurar $\mathrm{o}$ anonimato, eles foram caracterizados de P1 à P63.

Dos 63 docentes, $58 \%$ eram do sexo masculino, 45\% mestres, $29 \%$ doutores, $63 \%$ com 10 anos ou mais que estão no IFS e $52 \%$ lecionam disciplinas técnicas. Além disso, $55 \%$ dão aula no curso de Edificações e $50 \%$ no curso de alimentos. 
Pode-se observar que, apesar da pesquisa ter tido como objeto de estudo os cursos de Alimentos, Edificações e Química, a pesquisa retratou uma realidade de todos os cursos, visto que os docentes ensinam em diversos cursos.

Na primeira pergunta do questionário, evidenciou-se que a noção de EA, para $39 \%$ dos professores, é que é um processo educacional de conscientização dos indivíduos voltado para as questões ambientais. Alguns deram um conceito ainda mais aprofundado. Para o professor P3, EA: "É toda ação educativa que possa contribuir para despertar a preocupação individual e coletiva para as questões ambientais, garantindo acesso a informações claras e diretas que possam contribuir para o desenvolvimento de uma consciência crítica, que o torne apto a tomar decisões coletivas sobre as questões ambientais".

Por outro lado, $32 \%$ possuem uma percepção elementar de EA, pois a veem como simples ações ou expressões isoladas tais como: reciclar, coleta seletiva, preservar, conservar, não poluir, racionar ou desenvolvimento sustentável. Apesar da definição de desenvolvimento sustentável não ser superficial, não deve ser confundida com EA.

Para Roos e Becker (2012), a EA é uma forma de se obter a sustentabilidade, ou seja, o desenvolvimento sustentável, processo a longo prazo, pode ser um dos propósitos (fim) a ser alcançado através da EA (meio). Ainda em resposta à primeira questão, $13 \%$ dos professores entendem EA como tema transversal e interdisciplinar que precisa ser discutido na formação dos alunos.

$\mathrm{Na}$ segunda questão, os docentes do IFS foram indagados sobre se eles achavam que a temática ambiental deveria ser trabalhada nos Cursos Técnicos de Nível Médio Integrados ao Ensino Médio, 100\% dos professores responderam que sim. $42 \%$ justificaram que é papel da escola formar cidadãos (alunos) mais conscientes, críticos e preocupados ambientalmente, 18\% afirmaram que a escola tem a responsabilidade de formar profissionais que possam atuar nas suas áreas preocupados com o Meio Ambiente, e $8 \%$ disseram que auxiliaria a transmitir conhecimento sobre a Educação Ambiental e o desenvolvimento sustentável. Outras justificativas apareceram com menor incidência.

$\mathrm{Na}$ realidade, a temática ambiental deve estar presente não somente no nível médio na modalidade integrada, pois a EA "é um componente essencial e permanente da educação nacional, devendo estar presente, de forma articulada, em todos os níveis e modalidades do processo educativo, em caráter formal e não-formal" (BRASIL, 1999). Ou seja, infere-se que a EA deve transitar na educação infantil, no ensino fundamental, no ensino médio, na graduação e na pós-graduação.

Quando perguntados se conheciam os Parâmetros Curriculares Nacionais (PCN), 59\% responderam que sim, destes $32 \%$ falaram que tiveram acesso 
aos $\mathrm{PCN}$ no IFS, $23 \%$ na universidade, $18 \%$ na internet e $9 \%$ relataram que receberam os documentos. A parte dos $\mathrm{PCN}$ que mais chamou a atenção dos que conheciam os PCN foram: os temas transversais (36\%), a área relacionada à disciplina que leciona $(18 \%)$ e os currículos e conteúdos mostrando a proposta pedagógica (9\%). Outros pontos foram considerados pelos docentes: o apoio/suporte no planejamento e desenvolvimento das matrizes curriculares; a tentativa de criar parâmetros curriculares nacionais comuns; agrupar as disciplinas em áreas: Linguagens e Códigos; Ciências da Natureza e Matemática; e Ciências Humanas; quando aborda o crescimento da população e, consequentemente, o aumento do uso dos recursos naturais; contextualização dos assuntos; e a avaliação.

Dos 37 (59\%) professores que disseram conhecer os PCN, 27\% afirmaram que os $\mathrm{PCN}$ poderiam contribuir como norteador e orientador da sua prática docente, $24 \%$ com a inserção nas práticas pedagógicas dos temas transversais e $19 \%$ porque os PCN indicam caminhos de ações interdisciplinares.

Para Bomfim et al. (2013), os PCN se firmaram e atingiram mais as escolas do que as Diretrizes Curriculares Nacionais (DCN), quando deveria ser o inverso, uma vez que, como o próprio nome já diz, os $\mathrm{PCN}$, além de não serem obrigatórios, seriam apenas referências, parâmetros.

Essa maior aceitação dos PCN pode ser explicada pela perspectiva de Bonamino e Martínez (2002), que argumentam que os PCN, por serem instrumentos mais específicos e normativos, foram concebidos e encaminhados de forma a reorientar um instrumento de caráter mais abrangente como as DCN. Na opinião de Nunes (2012) os PCN, apesar das críticas, tornaram-se referência e têm sido apontados como norteadores para a elaboração de planejamentos nas escolas e mesmo para realização de avaliações do sistema escolar.

Posteriormente, foi perguntado aos professores se a temática ambiental é um dos conteúdos de sua disciplina. $66 \%$ dos docentes responderam que sim. Procurou-se saber de que modo eles abordam a temática ambiental em sala de aula. A maioria dos docentes, $78,9 \%$, aborda a temática ambiental relacionada ao assunto da disciplina que leciona. $13,2 \%$ respondeu que não aborda a temática, $2,6 \%$ que conversa com os alunos sobre o tema, $2,6 \%$ diz usar materiais recicláveis e $2,6 \%$ que abordam superficialmente.

Confrontando-se com o resultado obtidos com os alunos, no qual $77,1 \%$ disseram que "às vezes" ou "raramente" assuntos relacionados à temática ambiental são abordados em sala de aula e $90,8 \%$ dos alunos indicaram que a abordagem era feita relacionada ao conteúdo da disciplina, conclui-se, então, que a maior parte dos professores trabalham a temática ambiental articulada ao conteúdo da disciplina, porém com pouca frequência.

Para $34,2 \%$ dos professores, os alunos são receptivos à abordagem da temática ambiental em sala de aula. Outros $21,1 \%$ responderam que os alunos 
demonstram interesse, $15,8 \%$ relataram que eles discutem o tema e $7,9 \%$ que acham o tema importante. Ou seja, na opinião de $79 \%$ dos docentes, os discentes tem uma reação bem positiva.

Por fim, solicitou-se que os docentes apresentassem duas possibilidades concretas e duas dificuldades de articulação da temática ambiental aos conteúdos da disciplina que eles ministram.

A maioria, $60,5 \%$ dos professores, citou que aborda situações/exemplos relacionados a temática ambiental durante a explicação dos conteúdos. Uma alternativa bem citada, com $26,3 \%$, foi a apresentação e leitura de textos/trabalhos com a temática ambiental. As possibilidades apresentadas pelos docentes, somadas a outras maneiras de abordagem da temática ambiental, podem ser trabalhadas e aperfeiçoadas, através de capacitações, pois muitos enxergam as possibilidades, mas não as põem em prática.

Portanto, esses dados revelam que os professores têm noção das possibilidades de transmitir a EA através da sua disciplina, o que facilitaria a introdução do tema transversal na dinâmica escolar, falta apenas uma política no sentido de tornar efetiva a prática por todos da comunidade escolar.

Ações de ensino, pesquisa e extensão orientadas pelos princípios e objetivos da Política Nacional de Educação Ambiental já é realidade na Educação Profissional. Exemplo, é a Política Ambiental do Instituto Federal de Educação, Ciência e Tecnologia da Paraíba, que estabelece, dentre outras coisas, ações relativas ao meio ambiente no desenvolvimento dos projetos pedagógicos dos cursos (IFPB, 2015).

Já as dificuldades mais ressaltadas pelos professores foram: A temática ambiental não tem relação com a sua disciplina (23,7\%); Falta de tempo, pois o conteúdo da disciplina é extenso (21,1\%); Falta de conhecimento/preparo para trabalhar a temática ambiental (13,2\%); Dificuldade em realizar visitas técnicas $(13,2 \%)$. Porém, a resposta com mais incidência, com $28,9 \%$, foi que os docentes não enxergam dificuldades na articulação da temática ambiental com a sua disciplina.

Muitas das dificuldades apresentadas pelos professores se dão pela falta de preparo deles, tais como: falta de relação com sua disciplina; falta de conhecimento/preparo para trabalhar a temática; dificuldade em trabalhar a transversalidade; e até mesmo a falta de interesse dos alunos, que pode ser despertada.

As Diretrizes Curriculares Nacionais para a Educação Ambiental estabelecem, em seu art. 11, que a dimensão socioambiental deve constar dos currículos de formação inicial e continuada dos profissionais da educação, considerando a consciência e o respeito à diversidade multiétnica e multicultural do País. Além disso, estabelece que os professores em atividade devem receber formação complementar em suas áreas de atuação, com o propósito de atender de forma pertinente ao cumprimento dos princípios e objetivos da Educação Ambiental. 
A falta de capacitação dos docentes e dos profissionais envolvidos nas práticas pedagógicas das instituições de ensino dificulta um trabalho efetivo, baseado na transversalidade e a interdisciplinaridade.

Assim como este trabalho, Corrêa et al. (2006) relata em seu trabalho, realizado com 47 professores de 24 municípios da rede pública de ensino do estado de Goiás, que $66 \%$ dos professores não enxergavam dificuldades na abordagem da temática ambiental em suas disciplinas, porém o autor destaca que o trabalho com temas transversais requer, necessariamente, integração, disponibilidade, tempo, formação específica e incentivo. A simples reprodução de conteúdos do ensino tradicional é insuficiente. Apesar de apresentarem algum conhecimento sobre a complexidade inerente à transversalidade existem dificuldades em sua aplicação.

Lamosa e Loureiro (2011) realizaram um estudo em 25 escolas em Teresópolis $(\mathrm{RJ})$ e, em relação às dificuldades enfrentadas para a inclusão da EA nas escolas, cerca de $50 \%$ dos professores apontaram a precariedade de recursos materiais e humanos, bem como a falta de previsão de tempo para planejamento e realização de atividades extracurriculares como os principais problemas a serem enfrentados.

\section{Conclusões}

A implementação da Educação Ambiental em uma instituição, trabalhando para que o conceito de transversalidade chegue de forma efetiva à sala de aula, é complexo. Nem a legislação, através da Constituição Federal e da Política Nacional de Educação Ambiental, nem o lançamento de documentos oficiais, como os PCN e as Diretrizes Curriculares Nacionais para a Educação Ambiental, são garantias para a existência da Educação Ambiental nas instituições de ensino.

Por meio desse estudo, fica clara a necessidade de se institucionalizar a Educação Ambiental nos documentos pedagógicos do IFS, através de uma reformulação, para que eles sigam diretrizes e metas comuns em relação aos princípios e objetivos da Política Nacional de Educação Ambiental. E, mais do que isso, que estes documentos que regem e norteiam o ensino do IFS se inter-relacionem e se complementem. Ademais, é imprescindível a implementação de uma política voltada para a Educação Ambiental formal e não-formal, sendo respaldada por programas, com a sensibilização e a capacitação de todos os atores envolvidos do IFS.

\section{Agradecimentos}

Ao Instituto Federal de Sergipe - Campus Aracaju, que possibilitou a realização desse estudo; à Coordenação de Aperfeiçoamento de Pessoal de Nível Superior (CAPES) pela bolsa de Pós-Doutorado concedida à Kallyne Machado Bonifácio.

Revista brasileira educação ambiental 


\section{Referências}

BILERT, V.S.Z. et al. A Educação Ambiental nas universidades públicas estaduais do Paraná: uma análise a partir dos documentos institucionais. Revista Monografias Ambientais, v. 13, n. 4, p. 3444-3452, 2014.

BOMFIM, A.M. et al. Parâmetros curriculares nacionais: uma revisita aos temas transversais meio ambiente e saúde. Trabalho, Educação e Saúde, v.11, n.1, p. 27-52, 2013.

BONAMINO, A.; MARTÍNEZ, S.A. Diretrizes e Parâmetros Curriculares Nacionais para o Ensino Fundamental: a participação das instâncias políticas do Estado. Educação e Sociedade, v. 23, n. 80, p. 368-385, 2002.

BRASIL. Ministério da Educação. Parâmetros curriculares nacionais: ambiente, saúde. Brasília: MEC: SEF, 1997.

BRASIL. Lei n. 11.892, de 29 de dezembro de 2008. Disponível em: <http://www.planalto.gov.br/ccivil 03/ Ato2007-2010/2008/Lei/L11892.htm>.

Acesso em: 07 mai. 2020.

BRASIL. Lei n. 9.795, de 27 de abril de 1999. Disponível em: <http://www.planalto.gov.br/ccivil 03/LEIS/L9795.htm>. Acesso: 07 mai. 2020.

CORRÊA, S.A. et al. A Inserção dos Parâmetros Curriculares Nacionais (PCN) nas Escolas da Rede Pública do Estado de Goiás - Brasil: a Abordagem dos Temas Transversais - com Ênfase no Tema Meio Ambiente. Revista Eletrônica do Mestrado em Educação Ambiental, v.17, 2006.

DE-CARVALHO, R.; MATEI, A.P. Transversalizando conteúdos de Física no ensino médio: o efeito estufa causado pela pecuária. Ciência \& Educação, v. 25, n. 1, p. 255-266, 2019.

FREITAS et al. A Educação Ambiental como tema transversal no ensino básico e superior do Campus Porto Nacional - IFTO: análise quantitativa e proposta de intervenção Revista Brasileira de Educação Ambiental, v. 13, n. 2. p. 282293, 2018.

GIL, A.C. Métodos e Técnicas de Pesquisa Social. São Paulo: Atlas, 1995.

INSTITUTO FEDERAL DA APARAÍBA. Resolução n. 132, de 02 de outubro de 2015. Disponível em: <https://www.ifpb.edu.br/pre/assuntos/documentos-> Acesso em: 03 mai. 2020.

INSTITUTO FEDERAL DE SERGIPE. Plano de Desenvolvimento Institucional 2014-2019. 2015. Disponível em: <http://www.ifs.edu.br/ planejamento-e-gestao/plano-de-desenvolvimento-institucional-do-ifs $>$. Acesso em: 03 mar. 2017.

INSTITUTO FEDERAL DE SERGIPE. Projeto Pedagógico do Curso Técnico de Nível Médio Integrado ao Ensino Médio em Alimentos, 2014a. Disponível em: <http://www.ifs.edu.br/proen/index.php/ppc>. Acesso em: 03 mar. 2017. 
INSTITUTO FEDERAL DE SERGIPE. Projeto Pedagógico do Curso Técnico de Nível Médio Integrado ao Ensino Médio em Edificações, 2014b. Disponível em: <http://www.ifs.edu.br/proen/index.php/ppc>. Acesso em: 03 mar. 2017.

LAMOSA, R.A.C.; LOUREIRO, C.F.B. A Educação Ambiental e as políticas educacionais: um estudo nas escolas públicas de Teresópolis (RJ). Educação e Pesquisa, v. 37, n.2, p. 279-292, 2011.

OLIVEIRA. E.G.; SAITO, C.H. Análise do material didático PROBIO Educação Ambiental com foco na transversalidade curricular do tema meio ambiente. Revista Brasileira de Educação Ambiental, v.9, n. 2. p. 225-238, 2014.

RODRIGUES, A.P.S. O curso técnico em meio ambiente integrado ao ensino médio no estado do Paraná como alternativa para a formação integral dos jovens. Revista Brasileira de Educação Profissional e Tecnológica, v.1, p. 1 - 16, 2020.

ROOS, A.; BECKER, E. L. S. Educação Ambiental e Sustentabilidade. Revista Eletrônica em Gestão, Educação e Tecnologia Ambiental, v. 5, n. 5, p. 857 866, 2012.

SANTOS, A.G.; SANTOS, C.A.P. A Inserção da Educação Ambiental no Currículo Escolar. Revista Monografias Ambientais, v. 15, n.1, p. 369-380, 2016.

SEVERINO, A.J. Formação política do adolescente no Ensino Médio: a contribuição da Filosofia. Pro-Posições, v. 21, n. 1, p. 57-74,2010.

SILVA, J.A.; RAMOS, M.A. Contribuições da etnobiologia para formação continuada de professores de ciências da educação escolar quilombola. Revista Electrónica de Enseñanza de las Ciencias, v. 19, n. 1, p. 132-158, 2019.

VERGARA, S.C. Método de pesquisa em administração. Atlas: São Paulo, 2005.

VIÇOSA, C.S.C.L. et al. Meio ambiente como tema transversal no contexto de um curso experimental de curta duração e da metodologia da problematização. Revista Brasileira de Educação Ambiental, v.15, n. 1. p. 09-26, 2020.

UNITED NATION - UN. Transforming our World: The 2030 Agenda for Sustainable Development. 2015. Disponível em: $<$ https://sustainabledevelopment.un.org/post2015/transformingourworld/publicat ion> Acesso em: 05 mai. 2020. 